\title{
Calorie Restricted Diet and Urinary Pentosidine in Patients with Rheumatoid Arthritis
}

\author{
Kenichi Iwashige ${ }^{1,2)}$, Katsuyasu Kouda ${ }^{1,3)}$, Mitsuo Kouda ${ }^{4)}$, Kentaro Horiuchi ${ }^{5)}$, Masaaki Takahashi ${ }^{6}$, \\ Akira Nagano $^{6}$, , Toshiro Tanaka ${ }^{7)}$ and Hiroichi Takeuchi ${ }^{1)}$ \\ 1) Department of Public Health, Hamamatsu University School of Medicine \\ 2) Miyako Clinic \\ 3) Department of Hygiene, Kansai Medical University \\ 4) Kouda Clinic \\ 5) Department of Life Science, Hamamatsu University School of Medicine \\ 6) Department of Orthopedic Surgery, Hamamatsu University School of Medicine \\ 7) Third Department of Internal Medicine, School of Medicine, Osaka University
}

\begin{abstract}
Low-energy diets and fasting have suppressive effects on rheumatoid arthritis. It was reported recently that urine levels of pentosidine (i.e., an advanced glycation end product formed by glycosylation) is associated with the activity of rheumatoid arthritis. We conducted a regimen of caloric restriction combined with fasting in patients with rheumatoid arthritis, and then evaluated urinary pentosidine levels. Ten patients with rheumatoid arthritis underwent a 54day caloric restriction program. Urinary pentosidine levels were measured and the Lansbury Index were determined by examining the clinical features, blood biochemistry and the inflammation activity of rheumatoid arthritis on days 0,25 and 54 . On day 0 , the mean urinary pentosidine level of patients with rheumatoid arthritis was significantly higher than that of the control subjects. On day 54 , the mean body weight had reduced due to caloric restriction. The mean values of the erythrocyte sedimentation rate and the Lansbury Index of patients both significantly decreased during the study. In addition, although the urinary pentosidine levels showed no significant difference between day 0 and 25 , it was significantly decreased at the end of the study (day 54). The study showed that under a low energy diet a reduction of disease activity in rheumatoid arthritis was accompanied with a reduction of the urinary pentosidine. $J$ Physiol Anthropol Appl Human Sci 23 (1): 19-24, 2004 http://www.jstage.jst.go.jp/en/
\end{abstract}

Keywords: caloric restriction, fasting, rheumatoid arthritis, advanced glycation end-product (AGE), pentosidine

\section{Introduction}

It is well acknowledged that nutritional stress, such as dietary restriction or fasting, activates various responses. The dietary restriction extends life span and retards the development of chronic diseases (Weindruch and Walford, 1988); it also has beneficial effects on various inflammatory diseases (Fernandes G, 1978; Hishinuma, 1990; Kubo, 1987; Ogura, 1989). Fasting also has suppressive effects on inflammation (Nakamura, 2001); and the immediate consequences of fasting include marked increases in plasma cortisol, ACTH, beta-endorphin, beta-lipotrophic hormone, adrenaline, noradrenaline and dopamine (Becker, 1992; Beer, 1989; Brady, 1990; Komori, 1996).

Rheumatoid arthritis (RA) is a chronic, systemic inflammatory disease, resulting in the destruction of multiple joints (Firestein GS, 1992; Harris, 1990). Dietary regimens such as fasting, caloric restriction, or a vegetarian diet have the beneficial effects of improving the symptoms of patients with RA (Beri D, 1988; Forre, 1991; Hafström, 1998; KjeldsenKragh J, 1991; Sköldstam et al., 1979; Stroud, 1983; Udén et al., 1983).

It has been reported recently that the serum, urine and synovial fluid levels of pentosidine, correlated with the activities of RA (Chen, 1999; Chen, 1998; Takahashi, 1997). Urinary pentosidine, an advanced glycation end product (AGEs), is a glycoxidation damage biomarker (Chen, 1999; Takahashi, 1997; Takahashi, 1996). The nonenzymatic glycation and oxidation (glycoxidation) reaction of protein is thought to contribute to the cross-linking of tissue proteins, gumming up tissues, making them stiffer and less elastic, and so causing connective tissues to become leathery.

In the present study, we conducted a regimen of caloric 
restriction combined with fasting in patients with RA, and evaluated the disease activity by measuring urinary pentosidine levels.

\section{Methods}

\section{Subjects}

Ten Japanese female patients with RA (age; 58.2 \pm 4.8 year; range 48-77) were enrolled in this study. All of them were outpatients of Kouda Clinic located in Osaka. All participants gave informed consent, and the study procedures were in accordance with the Declaration of Helsinki. The patients were diagnosed on the American Rheumatism Association 1987 revised criteria (Arnett, 1988). The mean duration of RA was 6.6 years (range, 1-20). None of the patients had complications of cancers, diabetes mellitus, renal diseases, inflammatory disease or other autoimmune diseases, but one had hypertension.

Six patients took a non-steroidal anti-inflammatory drug (NSAID) and pre-donisolone daily. Their drug therapy had not changed for at least 3 months preceding the study. In five patients, doses of these drugs were diminished according to the degree of improvement in symptoms during the study. None needed an increase in their drugs during the clinical trial.

The control group consisted of 15 healthy females aged 43-80 year (60.2 \pm 6.0$)$. They were selected from the group of medical examination in our institution. There was no significant difference in age between RA patients and control subjects. All control subjects had no previous history of diabetes mellitus and renal disease, and were currently receiving no medication.

\section{Trial design and Diet arrangements}

Ten RA patients underwent a caloric restricted diet from days 0 to 10,14 to 24,31 to 43 , and 49 to 54. From day 11 to 13, 25 to 30 , and 44 to 48 , fasting was conducted (Fig. 1). On a calorie restriction day, the patients were given fresh vegetable juice (corresponding to $250 \mathrm{~g}$ of fresh vegetables) at breakfast to avoid any shortage of micronutrients that might accompany with dietary restriction. For lunch and dinner, they were given brown rice porridge (corresponding to $80 \mathrm{~g}$ of brown rice) sprinkled with $5 \mathrm{~g}$ of kelp powder, bean curd (tofu: wet weight $200 \mathrm{~g}$ ) and $10 \mathrm{~g}$ of sesame paste. The daily requirement of $2.5 \mathrm{~g}$
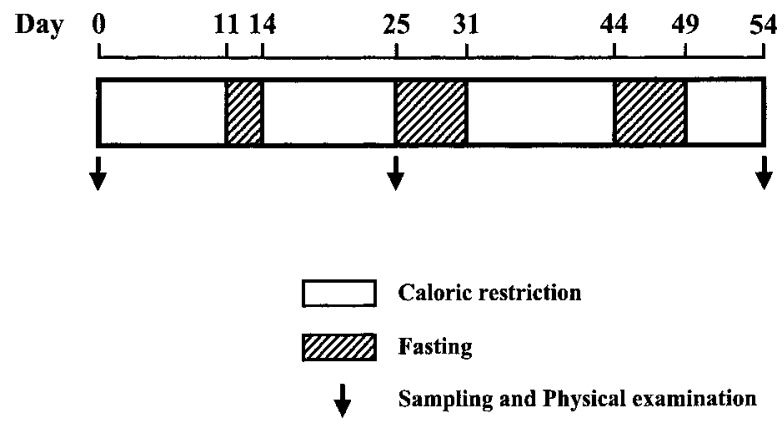

Fig. 1 The study of the caloric restriction program. of non-refined salt was also added to the diet. The energy intake $(1,085 \mathrm{kcal})$ was $55 \%$ constituted by nutritional requirements, while was protein $75 \%$, calcium $180 \%$, iron $130 \%$, vitamin A $150 \%$, vitamin C $250 \%$, and vitamin E $110 \%$ of daily requirements. On a fasting day, only vegetable soup $(720 \mathrm{kcal} /$ day) was served.

\section{Collection of serum and urine samples}

To measure blood urea nitrogen (BUN), Aspartate Aminotransferase (AST) and Alanine Aminotransferase (ALT), albumin, haemoglobin, erythrocyte sedimentation rate (ESR), and pentosidine, blood and urine samples were collected on the same day from all subjects between 7:00 and 9:00 a.m. on days 0,25 and 54. For an age-matched control group, 15 healthy volunteers ( 15 females), aged 35 to 68 years $(56.2 \pm 2.0)$ with no history of RA or the known disease also gave urine.

\section{Disease activity in $R A$}

The Lansbury Index (LI) was noted by a rheumatologist on days 0,25 and 54. LI was determined based on the duration of morning stiffness, erythrocyte sedimentation rate (ESR) (value at 1 hour), grip strength ( $\mathrm{mmHg}$ ) and joint score (Lansbury, 1966; Lansbury, 1957). The joint score was determined as the total sum for painful, tender or swollen joints.

\section{Measurement of urinary pentosidine}

The measurement of urinary pentosidine was performed as described (Takahashi, 1993). We identified the pentosidine in a hydrolysate of urine as the total form of pentosidine. After thawing, urine samples were centrifuged at $3000 \times \mathrm{g}$ for 10 minutes. A $0.5-\mathrm{ml}$ aliquot was hydrolyzed with an equal volume of $12 \mathrm{~mol} / 1$ hydrochloric acid at $110^{\circ} \mathrm{C}$ for $17 \mathrm{~h}$ in a sealed glass tube. Hydrolysate of urine $0.25-\mathrm{ml}$ was mixed with $15 \mathrm{ml}$ of water and applied to an SP-Sephadex C-25 column $\left(\mathrm{H}^{+}\right.$form, $0.8 \times 2.0 \mathrm{~cm}$; Pharmacia LKB Biotechnology AB, Uppsala, Sweden) that had been equilibrated with water. The column was washed with $20 \mathrm{ml}$ of $0.15 \mathrm{~mol} / 1$ hydrochloric acid. The elute evaporated under vacuum, and the residue dissolved in $200 \mu \mathrm{l}$ of $1 \%$ heptafluorobutyric acid. The solutions were stored at $-30^{\circ} \mathrm{C}$ for an analysis.

\section{High-performance liquid chromatography (HPLC)}

The HPLC system consisted of a Model LC-6A pump (Shimazu, Kyoto, Japan), a Model 474 spectrofluorometer (Waters Associates, Inc., Milford, MA), a Model AS-8020 autosampler (TOSOH, Tokyo, Japan), and a Model Chromatocorder 12 data processor (SIC, Tokyo, Japan). A column $(8 \mathrm{~mm} \times 10 \mathrm{~cm})$ prepacked with Radial-Pak C18, of 10$\mu \mathrm{m}$ particle size, type $8 \mathrm{C} 1810 \mu$ (Water Associates Inc., Milford, Mass, USA) was used. The flow rate was $1.0 \mathrm{ml} / \mathrm{min}$. The volume of each sample injected was $160 \mu \mathrm{l}$. For the detection of pentosidine, the fluorescence at $385 \mathrm{~nm}$ was measured on excitation at $335 \mathrm{~nm}$. The level of the pentosidine 
content in urine samples is expressed as the micromoles of the pentosidine per $1 \mathrm{~mol}$ of urinary creatinine. The urinary creatinine content was measured by a routine method. The standard pentosidine was donated by Dr.V. M. Monnier, Case Western Reserve University, School of Medicine, Cleveland, Ohio 44106, U.S.A.

\section{Statistical analysis}

Values are expressed mean \pm standard error. The unpaired $t$ test was used to compare the mean values of urinary pentosidine between the control subjects and RA patients. The paired $t$ test was used to compare the mean values of pentosidine, LI and other variables of RA patients.

\section{Results}

None of the participants dropped out of the study. Table 1 shows pathological and laboratory findings. A mean body

Table 1

\begin{tabular}{|c|c|c|c|}
\hline & $\begin{array}{c}\text { Before } \\
\text { Caloric } \\
\text { restriction }\end{array}$ & & $\begin{array}{c}\text { After } \\
\text { Caloric } \\
\text { restriction }\end{array}$ \\
\hline Day & 0 & 25 & 54 \\
\hline Body weight (kg) & $51.2 \pm 3.0$ & $48.8 \pm 2.6^{\ddagger}$ & $46.3 \pm 2.3^{\ddagger}$ \\
\hline S-Albumin (g/dl) & $4.3 \pm 0.1$ & $4.4 \pm 0.1$ & $4.5 \pm 0.1$ \\
\hline S-Hemoglobin (g/dl) & $12.5 \pm 0.4$ & $12.7 \pm 0.4$ & $13.1 \pm 0.2$ \\
\hline S-AST (IU/dl) & $17.8 \pm 1.7$ & $17.9 \pm 1.4$ & $18.3 \pm 0.8$ \\
\hline S-ALT (IU/dl) & $10.0 \pm 1.7$ & $8.8 \pm 1.4$ & $10.3 \pm 1.6$ \\
\hline S-BUN (mg/dl) & $8.5 \pm 0.8$ & $8.6 \pm 1.1$ & $8.8 \pm 1.0$ \\
\hline $\operatorname{ESR}(\mathrm{mm} / \mathrm{h})$ & $48 \pm 11.8$ & $33.3 \pm 10.4^{\dagger}$ & $23.3 \pm 8.0$ \\
\hline
\end{tabular}

Values are expressed mean \pm SEM $(n=10)$, S: Serum, AST: Aspartate Aminotransferase, ALT: Alanine Aminotransferase, BUN: Blood urea nitrogen, ESR: Erythrocyte sedimentation rate, ${ }^{\dagger} \mathrm{p}<0.05,{ }^{\ddagger} \mathrm{p}<0.01$. The statistical significance of differences was evaluated using paired t-test. The statistical analysis refers to the comparison with the values from day 0 .

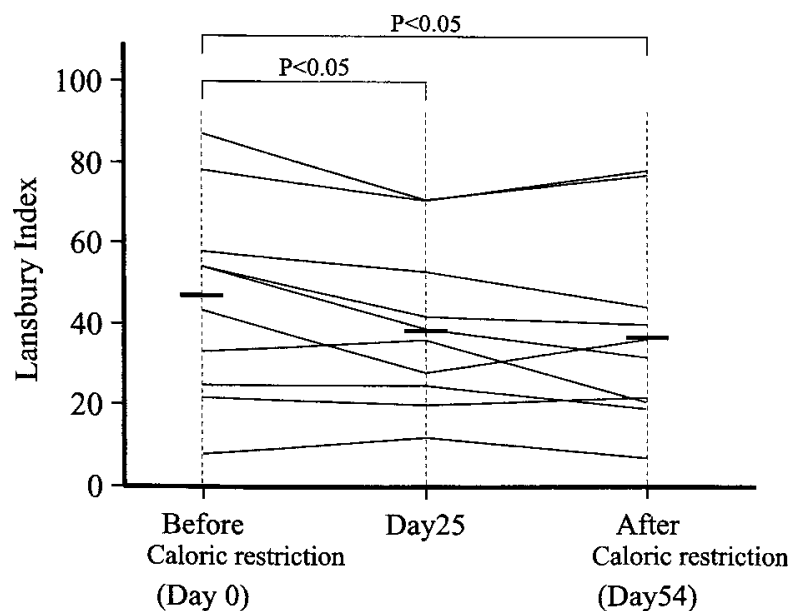

Fig. 2 Effects of the caloric restriction on the Lansbury index (LI) of 10 RA patients on days 0,25 and 54 . Horizontal bars indicate mean values. Significant difference was determined by paired $t$ test. weight of $2.4 \mathrm{~kg}$ of was lost by day 25 of the study, and at the end of the study $4.9 \mathrm{~kg}$ (day 54). But, the mean hemoglobin and serum albumin concentrations showed no significant changes during the study. The ESR decreased in 9 patients and the mean ESR showed a significant decrease by day 25 and at day 54 from baseline. There were no statistical differences in serum concentrations of BUN, or liver enzymes such as AST and ALT.

Before caloric restriction (day 0), the mean value of LI was $46.2 \pm 7.9 \%$. It decreased significantly during the study: $39.7 \pm 6.4 \%(\mathrm{P}<0.05$ vs. day 0$)$ on day 25 , and $37.6 \pm 7.5 \%$ $(\mathrm{P}<0.05$ vs. day 0$)$ on day 54 (Fig.2).

The mean value of urinary pentosidine in RA patients was significantly higher than that in control subjects: $4.20 \pm$

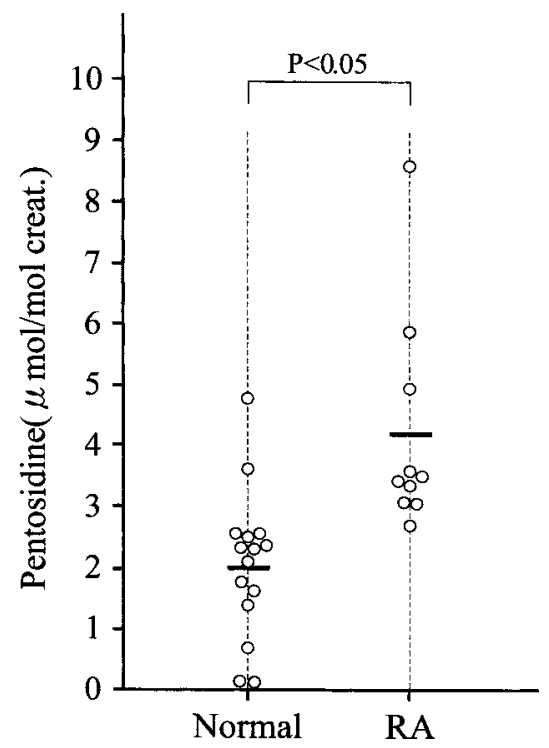

Fig. 3 Comparison between the levels of urinary pentosidine in 10 patients with rheumatoid arthritis (RA) and 15 control subjects on day 0 . Horizontal bars indicate the mean values. Significant difference was determined by the unpaired $t$ test.

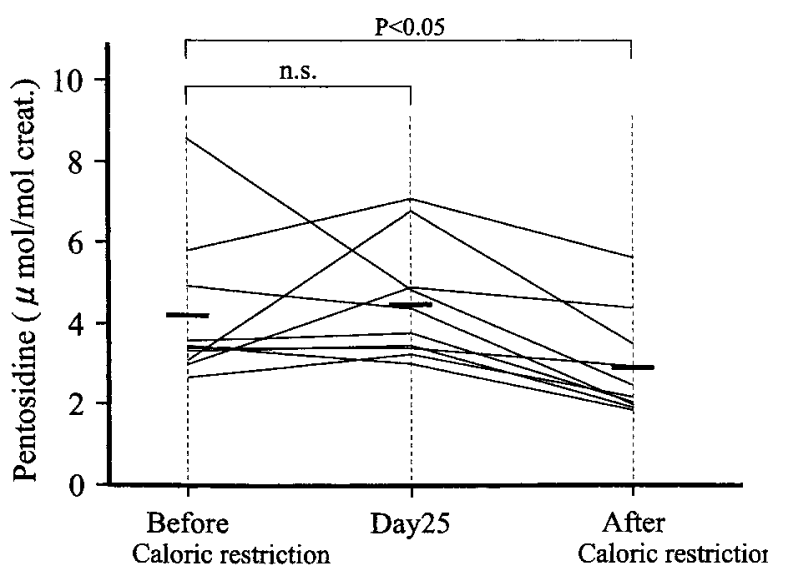

(Day 0)

(Day54)

Fig. 4 Effects of caloric restriction on urinary pentosidine levels of 10 RA patients on days 0,25 and 54. Horizontal bars indicate the mean values. Significant difference was determined by the paired $t$ test. 
$0.57 \mu \mathrm{mol} / \mathrm{mol}$ creatinine vs. $2.04 \pm 0.31 \mu \mathrm{mol} / \mathrm{mol}$ creatinine $(\mathrm{p}<0.01)$ (Fig. 3). In RA patients, there was no significant difference in the urinary pentosidine levels between days 0 and $25(4.20 \pm 0.57$ vs. $4.50 \pm 0.46 \mu \mathrm{mol} / \mathrm{mol}$ creatinine, $\mathrm{p}=0.60)$. However, the urinary pentosidine levels significantly decreased at the end of the study (day 54) compared with the baseline $(2.87 \pm 0.36$ vs. $4.20 \pm 0.52 \mu \mathrm{mol} / \mathrm{mol}$ creatinine, $\mathrm{P}<0.05)$ (Fig. 4).

\section{Discussion}

The pentosidine is one of the advanced glycation endproducts (Monnier, 1992; Sell, 1989; Uchiyama, 1991), and formation of pentosidine was accelerated in the increased sugars concentrations. Accelerated formations of pentosidine in diabetes mellitus (Takahashi, 1993) and in atherosclerotic cardiovascular disease (Uchiyama, 1991) have been reported. Recently, Takahashi et al. (1997) reported that the serum and urine levels of the pentosidine are correlated with the RA activity and then proposed that the serum and urine pentosidine might be a significant novel marker for evaluating RA disease status. In addition, dietary regimens such as fasting, caloric restriction, or vegetarian diet have the beneficial effects by improving symptoms of patients with RA (Beri D, 1988; Hafström, 1998; Kjeldsen-Kragh J, 1991). In the present study, the urine level of pentosidine in patients was significantly higher than that of control females. In addition, we demonstrated a reduction of the pentosidine in patients with RA by calorie restriction, with a simultaneous reduction of the Lansbury Index representing RA disease activity. Furthermore, a reduction of the pentosidine was accompanied by a significant reduction in body weight. This is consistent with previous reports (Kouda et al., 2000; Tanaka et al., 2001). However, the serum albumin, hemoglobin, BUN, AST and ALT were not significantly changed during calorie restriction, although ESR was significantly reduced. These results indicated that a low-energy diet does not malnourish participants, but has a suppressive effect on inflammatory diseases.

The actual mechanism for the reduction of the pentosidine by calorie restriction is unclear. In our study, we combined 3-6 days fasting after the 9-13 days caloric restriction. Previously, it has been hypothesized that the pentosidine formation is accelerated in pathological conditions accompanied with oxidative stress (Kouda et al., 2001; Oya et al., 1997; Suzuki et al., 1999). In animal and clinical studies, the calorie restriction decreases in oxidative damage to tissues (Yu, 1996). The previous reports have demonstrated that the calorie restriction reduces inflammations of dermatitis and the oxidative DNA damage derived from inflammation (Fan et al., 2001: Kouda et al., 2000; Tsuboi et al., 1998). In addition, the caloric restriction results in a decrease in the age-dependent accumulation of glycoxidation products, such as the pentosidine, in tissue (Cefalu et al., 1995; Iqbal et al., 1999; Reiser et al., 1994; Sell et al., 1997; Sell et al., 1996).
Furthermore, the fasting reduces food intolerance (Panush, 1986), diminishes the gastrointestinal permeability (Sundqvist, 1982) and decreases the intake of inflammatory mediators, prostaglandins and leukotrienes (Darlington, 1986). Further, the foodstuffs used in this study were rich in antioxidant. It has been reported that a diet antioxidant and fruites may have an antioxidant effects (Fan WY et al., 2000; Pool-Zobel et al., 1997; Thompson et al., 1999; Verhagen et al., 1997). A complex combination of these mechanisms might relate to the present results.

In conclusion, under a low energy diet the reduction of a RA disease activity was accompanied with a reduction of the urinary pentosidine.

Acknowledgements The authors thank all participants of this study, Dr. Monnier VM (Case Western Reserve University) for the gift of standard pentosidine, Mr. Lin R (Hamamatsu University School of Medicine) and $\mathrm{Mr}$. Yamashima T (Hamamatsu University School of Medicine) for assistance with the measurement of urinary pentosidine.

\section{References}

Arnett FC, Edworthy SM, Bloch DA, McShane DJ, Fries JF, Cooper NS, Healy LA, Kaplan SR, Liang MH, Luthra HS, Medsger TA, Mitchell DM, Neustadt DH, Pinals RS, Schaller JG, Sharp JT, Wilder RL, Hunder GG (1988). The American Rheumatism Association 1987 revised criteria for classification of rheumatoid arthritis. Arthritis Rheum 31: 315-324

Becker BA, Niwano Y, and Johnson HD (1992) Physiologic and immune responses associated with 48-hour fast of pigs. Lab Anim Sci 42: 51-53

Beer SF, Bircham PM, Bloom SR, Clark PM, Hales CN, Hughes CM, Jones CT, Marsh DR, Raggatt PR, Findlay AL (1989) The effect of a 72-h fast on plasma levels of pituitary, adrenal, thyroid, pancreatic and gastrointestinal hormones in healthy men and women. J Endocrinol 120: 337-350

Beri D, Malaviya AN, Shandilya R, Singh RR (1988) Effect of dietary restrictions on disease activity in rheumatoid arthritis. Annals of the Rheumatic Disease 47: 69-72

Brady LS, Smith MA, Gold PW, Herkenham M (1990) Altered expression of hypothalamic neuropeptide mRNAs in foodrestricted and food-deprived rats. Neuroendocrinology 52: 441-447

Cefalu WT, Bell-Farrow AD, Wang ZQ, Sonntag WE, Fu MX, Baynes JW, Thorpe SR (1995) Caloric restriction decreases age-dependent accumulation of the glycoxidation products, $\mathrm{N}$ epsilon-(carboxymethyl)lysine and pentosidine, in rat skin collagen. J Gerontol A Biol Sci Med Sci 50: B337-B341

Chen JR, Takahashi M, Suzuki M, Kushida K, Miyamoto S, Inoue $\mathrm{T}$ (1999) Comparison of the concentrations of pentosidine in the synovial fluid, serum and urine of patients with rheumatoid arthritis and osteoarthritis. Rheumatology (Oxford) 38: 1275-1278 
Chen JR, Takahashi M, Suzuki M, Kushida K, Miyamoto S, Inoue T (1998) Pentosidine in Synovial fluid in osteoarthritis and rheumatoid arthritis: relationship with disease activity in rheumatoid arthritis. J Rheumatol 25: 2440-2444

Darlington LG, Ramsey NW, Mansfield JR (1986) Placebocontrolled, blind study of dietary manipulation therapy in rheumatoid arthritis. Lancet 1: 236-238

Fan WY, Ogusu K, Kouda K, Nakamura H, Satoh T, Ochi H, Takeuchi H (2000) Reduced oxidative DNA damage by vegetable juice intake: A control trial. J Physiol Anthropol Appl Human Sci 19(6): 287-289

Fan WY, Kouda K, Nakamura H, Takeuchi H (2001) Effects of dietary restriction on spontaneous dermatitis in $\mathrm{NC} / \mathrm{Nga}$ mice. Exp Biol Med 226: 1045-1050

Fernandes G, Friend P, Yunis EJ, Good RA (1978) Influence of dietary restriction on immunologic function and renal disease in (NZB/NZW) F1 mice. Proc Natl Acad Sci USA 75: 1500-1504

Firestein GS (1992) Mechanism of tissue destruction and cellular activation in rheumatoid arthritis. Curr Opin Rheumatol 4: 348-354

Forre O (1991) Controlled trial of fasting and one-year vegetarian diet in rheumatoid arthritis. Lancet 338: 899-902

Hafström I, Ringerz B, Gyllenhammar H, Palmblad J, HarmsRingdahl M (1998) Effects of fasting on disease activity, neutrophil function, fatty acid composition, and leukotriene

biosynthesis in patients with rrheumatoid arthritis. Arthritis and Rheumatism 31: 585-592

Harris ED Jr. (1990) Rheumatoid arthritis. Pathophysiology and implications for therapy. N Engl J Med 322: 1277-1289

Hishinuma K, Nishimura T, Konno A, Hashimoto Y, Kimura S (1990) Augmentation of mouse immune functions by dietary restriction: An investigation up to 1year of age. Ann Nutr Metab 34: 76-84

Iqbal M, Kenney PB, Klandorf H (1999) Age-related changes in meat tenderness and tissue pentosidine: Effect of diet restriction and aminoguanidine in broiler breeder hens. Poult Sci 78: 1328-1333

Kjeldsen-Kragh J, Haugen M, Borchgrevink CF, Laerum E, Eek M, Mowinkel P, Hovi K, Komori T, Fujiwara R, Shizuya K, Miyahara S, and Nomura J (1996) The influence of physical restraint or fasting on plaque-forming cell response in mice. Psychiatry Clin Neurosci 50: 295-298

Kouda K, Nakamura H, Fan WY, Horiuchi K, Takeuchi H (2001) The relationship of oxidative DNA damage marker 8hydroxydeoxyguanosine and glycoxidative damage marker pentosidine. Clin Biochem 34: 247-250

Kouda K, Tanaka T, Kouda M, Takeuchi H, Takeuchi A, Nakamura H, Takigawa M (2000) Low-energy diet in atopic dermatitis patients: clinical findings and DNA damage. J Physiol Anthropol Appl Human Sci 19: 225-228

Kubo C, Johnson BC, Gajjar A, Good RA (1987) Crucial dietary factors in maximizing life span and longevity in autoimmune-prone mice. J Nutr 117: 1129-1135

Lansbury J (1957) Numerical metnod of evaluating the status of rheumatoid arthritis. Ann Rheum Dis 16: 101-107

Lansbury J (1966) Methods for evaluating rheumatoid arthritis. In: Hollander JL, ed., Arthritis and Allied Conditionsk. Lea and Febiger, Philadelphia, 269-291

Monnier VM, Sell DR, Nagaraj RH, Miyata S, Grandhee S, Odetti P, Ibrahim SA (1992) Maillard reaction-mediated molecular damage to extracellular matrix and other tissue ptoteins in diabetes, aging, and uremis. Diabetes 41 (Suppl 2): $36-41$

Nakamura H, Kouda K, Fan WY, Watanabe T, Takeuchi H (2001) Suppressive effects on allergic contact dermatitis by short-term fasting. Toxicol Pathol 29: 200-207

Ogura M, Ogura H, Ikehara S, Good RA (1989) Influence of dietary energy restriction on the numbers and proportions of Ly- $1^{+}$B lymphocytes in autoimmunity-prone mice. Proc Natl Acad Sci USA 86: 4225-4229

Oya T, Osawa T, Kawakishi S (1997) Spice constituents scavenging free radicals and inhibiting pentosidine formation in a model system. Biosci Biotechnol Biochem 61: 263-266

Panush RS, Stroud RM, Webster EM (1986) Food-induced (allergic) Arthritis: inflammation arthritis exacerbated by milk. Arthritis Rheum 29: 220-226

Pool-Zobel BL, Bub A, Muller H, Wollowiski I, Rechkemmer G (1997) Consumption of vegetables reduces genetic damage in humans: first results of a human intervension tiral with carotenoid-rich foods. Carcinogenessis 18: 1847-1850

Reiser KM (1994) Influence of age and long-term dietary restriction on enzymatically mediated crosslinks and nonenzymatic glycation of collagen in mice. Gerontol 49: B71-B79

Sell DR, Monnier VM (1997) Age-related association of tail tendon break time with tissue pentosidine in $\mathrm{DBA} / 2$ vs C57BL/6 mice: the effect of dietary restriction. J Gerontol A Biol Sci Med Sci 52: B277-B284

Sell DR, Lane MA, Johnson WA, Masoro EJ, Mock OB, Reiser KM, Fogarty JF, Cutler RG, Ingram DK, Roth GS, Monnier VM (1996) Longevity and the genetic determination of collagen glycoxidation kinetics in mammalian senescence. Proc Natl Acad Sci USA 93: 485-490

Sell DR, Monnier VM (1989) Structure elucidation of a senescence cross-link from human extracellular matrix. J Biol Chem 264: 21597-21602

Sköldstam L, Larsson L, Lindström F (1979) Effects of fasting and lactovegetarian diet on rheumatoid arthritis. Scand J Rheumatol 8: 249-255

Stroud RM (1983) The effect of fasting followed by specific food challenge on rheumatoid arthritis, Current Topics in Rheumatology. In Kahn BH, Arnett FC, Zizic TM, Hochberg MC, eds., Upjohn, Kalamazoo

Sundqvist T, Lindsröm F, Magnusson KE, Skoldstam L, Stjernstrom I, Tagesson C (1982) Influence of fasting on intestinal permeability and disease activity in patients with rheumatoid arthritis. Scand J Rheumatol 11: 33-38 
Suzuki D, Miyata T, Saotome N, Horie K, Inagi R, Yasuda Y, Uchida K, Izuhara Y, Yagame M, Sakai H, Kurokawa K (1999) Immunohistochemical evidence for an increased oxidative stress and carbonyl modification of proteins in diabetic glomerular lesions. J Am Soc Nephrol 10: 822-832

Takahashi M, Suzuki M, Kushida K, Miyamoto S, Inoue T (1997) Relationship between pentosidine levels in serum and urine and activity in rheumatoid arthritis. $\mathrm{Br} \mathrm{J}$ Rheumatol 36: 637-642

Takahashi M, Hoshino H, Kushida K, Kawana K, Inoue T (1996) Direct quantification of pentosidine in urine and serum by HPLC with column switching. Clin Chem 42: 000-000.

Takahashi M, Ohishi T, Aoshima H, Kawana K, Kushida K, Inoue T, Horiuchi K (1993) The Maillard ptotein cross-link pentosidine in urine from diabetic patients. Diabetologia 36: 664-667

Tanaka T, Kouda K, Kotani M, Takeuchi A, Tabei T, Masamoto Y, Nakamura H, Takigawa M, Suemura M, Takeuchi H, Kouda M (2001) Vegetarian diet ameliorates symptoms of atopic dermatitis through reduction of the number of peripheral eosinophils and of PGE2 synthesis by monocytes. J Physiol Anthropol Appl Human Sci 20: 353-361

Thompson HJ, Heimendinger J, Haegele A, Sedlacek SM, Gillette C, O’Neill C, Wolfe P, Conry C (1999) Effect of increased vegetable end fruit consumption on markers of oxidative cellular damage. Carcinogenesis 20: 2261-2266

Tsuboi H, Kouda K, Takeuchi H, Takigawa M, Masamoto Y,
Takeuchi M, Ochi H (1998) 8-hydroxydeoxyguanosine in urine as an index of oxidative damage to DNA in the evaluation of atopic dermatitis. Br J Dermatol 138: 10331035

Uchiyama A, Ohishi T, Takahashi M, Kushida K, Inoue T, Fujie M, Horiuchi K (1991) Fluorophores from aging human articular cartilage. J Biochem 110: 714-718

Udén AM, Trang L, Venizeloz N, Palmblad J (1983) Neutrophil function and clinical performance after total fasting in patients with rheumatoid arthritis. Ann Rheum Dis 42: 45-51

Verhagen H, de Vries A, Nijhoff WA, Schouten A, van Poppel G, Peters WHM, van den Berg H (1997) Effect of Brussels sprouts on oxidative DNA-damage in man. Cancer Lett 114: 127-130

Weindruch R, Walford RL (1988) The retardation of aging and disease by dietary restriction. Charles C Thomas, Springfield

Yu BP (1996) Aging and oxidative stress: Modulation by dietary restriction. Free Radic Biol Med 21: 651-668

Received: September 8, 2003

Accepted: December 15, 2003

Correspondence and proofs to: Kenichi Iwashige, 312-502, Miyako Clinic Uradeyama-cho, Nakagyo-ku, Kyoto, Kyoto 604-8155, Japan

Phone: +81-75-254-1163

Fax: +81-75-254-1165

e-mail: iwashige@miyako-clinic.jp 